\title{
Small-bowel mucosal changes in Egyptian cirrhotic patients with portal hypertension using capsule endoscopy versus single- balloon enteroscopy
}

\author{
Zienab M. Saad ${ }^{1 *}$ (D), Ali H. El-Dahrouty ${ }^{1}$, Amr M. El-Sayed ${ }^{1}$, Hesham K. H. Keryakos² ${ }^{2}$ Nancy N. Fanous ${ }^{3}$ and
} Ibrahim Mostafa ${ }^{4}$

\begin{abstract}
Background: Small-bowel mucosal abnormalities that may occur secondary to portal hypertension in patients with liver cirrhosis have an impact on health and quality of life. In spite of the importance of these changes, little is known about the frequency and features of small-bowel changes in cirrhotic patients with portal hypertension. Eighty cirrhotic patients with or without esophageal or gastric varices were recruited in this study as well as 60 ageand sex-matched controls. All study participants underwent capsule endoscopy. In addition, half of the patients and controls were randomized to receive single-balloon enteroscopy.

Results: The prevalence of small-bowel mucosal changes was statistically significantly higher in cirrhotic patients than in controls; $57 \%$ versus $6.7 \%$, respectively $(p<0.05)$. Cirrhotic patients with portal hypertensive gastropathy showed a significant increase in the small-bowel changes $(p<0.001)$. Small-bowel changes were significantly higher in patients with higher MELD and Child-Pugh scores $(p<0.001)$. Moreover, capsule endoscopy was more effective in the detection of small-bowel changes than single-balloon enteroscopy.

Conclusions: Mucosal changes associated with portal hypertensive enteropathy are more prevalent in cirrhotic patients, regardless of the presence or absence of gastric varices. Small-bowel mucosal changes in patients with portal hypertensive enteropathy were more common in patients who suffered from portal hypertensive gastropathy and were positively correlated with advanced chronic liver disease.
\end{abstract}

Keywords: Cirrhosis, Portal hypertension, Small bowel, Capsule endoscopy, Balloon enteroscopy

\section{Background}

Liver cirrhosis represents a major public health problem in Egypt, due to the high prevalence of viral hepatitis; mainly chronic hepatitis C (up to 10\%) [1], and less commonly chronic hepatitis B (approximately 1.4\%) [2]. Liver cirrhosis result in scaring of normal liver tissue with loss of normal hepatic architecture which cause increased vascular resistance and contribute to subsequent portal hypertension [3]. Portal hypertension causes both mucosal and vascular changes along the entire

\footnotetext{
* Correspondence: Zenab.Saad@mu.edu.eg

'Department of Tropical Medicine; Faculty of Medicine, Minia University,

Aswan-Cairo Agricultural Road, El-Minya 61111, Egypt

Full list of author information is available at the end of the article
}

gastrointestinal tract including esophageal and gastric varices, portal hypertensive gastropathy (PHG), portal hypertensive colopathy (PHC), and portal hypertensive enteropathy (PHE), which refers to the mucosal and vascular changes of the small intestine that are associated with portal hypertension [4]. The identification and diagnosis of PHE have evolved over the past decade due to increased accessibility of the small intestine with the use of video capsule endoscopy (VCE) and deep enteroscopy [5].

There is no consensus classification of PHE. De Palma et al. classified endoscopic findings of PHE into two categories; mucosal inflammatory-like abnormalities (edema, erythema, granularity, friability), and vascular lesions 
(cherry-red spots, telangioectasia, or angiodysplasia-like lesions, varices) [6]. Meanwhile, Abdelaal et al. classified PHE lesions into 4 subtypes; inflammatory-like lesions, red spots, angioectasia, and small-bowel varices [7].

To the best of our knowledge, this is the first study of Egyptian patients with liver cirrhosis and portal hypertension using small-bowel capsule endoscopy or singleballoon enteroscopy. We aimed in this study to study the small-bowel mucosa of cirrhotic patients with portal hypertension and to compare the diagnostic accuracy between $\mathrm{CE}$ and enteroscopy.

\section{Methods}

\section{Study design and data collection}

This prospective, controlled study was carried out at Minia University Hospital, department of tropical medicine, and at Wadi Elneel Hospital, unit of gastroenterology and endoscopy. This study included 140 adult subjects, 80 known cirrhotic patients and 60 controls. All patients were selected from both the outpatient and inpatient clinics.

This study consisted of three groups: group one included 40 cirrhotic patients who did not suffer from any esophageal or gastric varices, group two included 40 cirrhotic patients who suffered esophageal or gastric varices (as previously diagnosed by upper gastroduodenal endoscopy), and group three included 60 controls who did not suffer from any chronic liver diseases and were indicated for small-bowel capsule endoscopy or enteroscopy either due to unexplained abdominal pain, chronic diarrhea, or obscure GIT bleeding.

Patients were excluded from the study if they had or suspected to have intestinal obstruction or strictures; they had recent history or current intake of medications which affect the degree of portal hypertension, such as beta-blockers, and affect the intestinal mucosa, such as non-steroidal anti-inflammatory drugs; they suffered from renal or cardiac impairment, hepatocellular carcinoma, and/or portal vein thrombosis; they suffered from enteritis from other causes, such as Crohn's disease; and if they suffered from swallowing disorders.

Data collected from patients included age; gender; presence or absence of chronic liver diseases documented by history; clinical examination; laboratory Investigation including $\mathrm{CBC}$, liver function, renal function, and viral hepatitis markers; presence or absence of cirrhosis documented by abdominal ultrasonography, presence or absence of GI-tract abnormalities; esophageal and gastric varices; and portal hypertensive gastropathy (PHG) documented by upper GIT endoscopy.

Liver cirrhosis was diagnosed using typical history and clinical features of chronic liver diseases, abnormal synthetic functions, typical radiological features, and/or histological data of liver cirrhosis or evidence of cirrhosis by transient elastography. Liver cirrhosis severity was determined using Child-Pugh class and MELD score [8].

Small-bowel changes were defined as mucosal inflammatory-like abnormalities (edema, erythema, granularity, friability, and/or spontaneous bleeding) and/ or vascular lesions (cherry-red spots, telangioectasia, or angiodysplasia-like lesions and varices). All patients received capsule endoscopy.

Twenty patients from group I, twenty patients from group II, and thirty controls from group III were randomly selected to receive single-balloon enteroscopy to study its accuracy of diagnosis with that of CE.

Capsule endoscopy of the small bowel was done using CAM SB2 Capsule, GIVEN IMAGING LTD, as it enabled minimally invasive visualization of the GI tract. Patients stopped taking any iron-containing medications 1 week before capsule endoscopy. Patients stopped taking any solid food and any dark food the night prior to the procedure, started a clear liquid diet, then started 1 $\mathrm{L}$ of polyethyl glycol plus simethicone to improve SB visualization. Then, patients fasted for $12 \mathrm{~h}$ before the procedure. The patient ingested the capsule with a cup of water then took nothing per mouth for $2 \mathrm{~h}$, after $2 \mathrm{~h}$ one glass of water, light snack after $4 \mathrm{~h}$, and regular diet after $6 \mathrm{~h}$ and was observed for $8 \mathrm{~h}$ at the study site. After $8 \mathrm{~h}$, the sensor array and the recording device were removed. After completion of the imaging study, patients were permitted to return home. The CE digital image stream was reviewed and interpreted by two expert endoscopists.

Single-balloon enteroscopy was done using video scope OLYMPUS SIF Type Q260. No bowel preparation is generally recommended in most cases for single-balloon enteroscopy by the oral approach, except a minimum of $12 \mathrm{~h}$ fasting, deep monitored sedation with propofol or general anesthesia with intubation is recommended for antegrade approach.

\section{Statistical analysis}

Analyses of data were done using Statistical Package of Social Science (SPSS), version 20. Qualitative data expressed as proportions, while quantitative data expressed as the mean \pm standard deviation (SD). The Student's $t$ test and one-way ANOVA were used for comparison of quantitative variables. Qualitative data was analyzed by chi-square $(x 2)$ test. Pearson's correlation coefficient was used to measure the strength of a linear association between two variables and is denoted by $r$. Logistic regression is a statistical method for analyzing a data set in which there are one or more independent variables that determine an outcome. Statistical significance was defined as $p$ values less than 0.05 . 


\section{Results}

A total of 140 patients who fulfilled the inclusion criteria of the study, eighty of them were patients with liver cirrhosis that further divided into two groups, group I included forty cirrhotic patients without esophageal or gastric varices. Group II included forty cirrhotic patients with esophageal and gastric varices (as diagnosed by upper endoscopy). Group III (control group) included sixty non-cirrhotic patients who underwent capsule endoscopy for causes like anemia (obscure GIT bleeding) chronic diarrhea or chronic abdominal pain.

All the studied groups completed the CE and singleballoon enteroscopy uneventfully without complications.

Characteristics and small-bowel findings of the studied groups are listed in Table 1.

The mean of the age was $34.85 \pm 6.32$ years old in group I, $35.85 \pm 9.3$ years old in group II, and $37.67 \pm 8$ years old in group III with insignificant difference $p=$ 0.45 .

According to sex, in group I $20 \mathrm{M} / 20 \mathrm{~F}$, in group II 22 $\mathrm{M} / 18 \mathrm{~F}$, in group III $32 \mathrm{M} / 28 \mathrm{~F}$ without significant difference $p=0.95$.

The etiology of liver cirrhosis in all patients was post hepatitis distributed as in group I 36/40 (90\%) HCV and
4/40 (10\%) HBV. In group II 34/40(85\%) HCV and 6/ $40(15 \%) \mathrm{HBV}$, with insignificant difference.

Using capsule endoscopy, small-bowel changes were detected in $22 / 40(55 \%)$ in group I, $24 / 40(60 \%)$ in group II, and 4/60 (6.6\%) in group III with insignificant difference between groups I and II but highly significant difference when compared with the control group $p<0.001$.

Inflammatory changes were associated with vascular changes in $10 / 40(25 \%)$ in group I and in $16 / 40(40 \%)$ in group II.

The pattern of small-bowel mucosal changes was assessed according to inflammatory and vascular changes.

Edematous villi and erosions were detected in $4 / 40$ $(10 \%)$ in group I and $10 / 40(25 \%)$ in group II, in $2 / 60$ (3.3\%) in group III.

Angioectasia in 6/40 (15\%) in group I, and not detected in group II OR III.

Varices in $2 / 40(5 \%)$ in group I, $4 / 40(10 \%)$ in group II, not in group III. Edematous villi and erosions + angioectasia 4/40 (10\%) in group I, 4/40 (10\%) in group II, not in group III (Fig. 1).

Edematous villi and erosions + varices in 2/40 (5\%) in group I, 2/40 (5\%) in group II.

Table 1 Characteristics and small bowel changes in studied groups

\begin{tabular}{|c|c|c|c|c|}
\hline & Group I & Group ॥ & Group III & $p$ value \\
\hline & No varices & With varices & Control & \\
\hline & $N=40$ & $N=40$ & $N=60$ & \\
\hline \multicolumn{5}{|l|}{ Age } \\
\hline Range & $26-48$ & $25-50$ & $25-54$ & 0.45 \\
\hline Mean \pm SD & $34.85 \pm 6.32$ & $35.85 \pm 9.3$ & $37.67 \pm 8$ & \\
\hline \multicolumn{5}{|l|}{ Sex } \\
\hline Male N (\%) & $20(50 \%)$ & $22(55 \%)$ & $32(53.3 \%)$ & 0.9 \\
\hline Female N (\%) & $20(50 \%)$ & $18(45 \%)$ & $28(46.7 \%)$ & \\
\hline Etiology & & & & ns \\
\hline $\mathrm{HCV}$ & $36(90 \%)$ & $34(85 \%)$ & & \\
\hline HBV & $4(10 \%)$ & $6(15 \%)$ & & \\
\hline Small bowel changes & $22(55 \%)$ & $24(60 \%)$ & $4(6.6 \%)$ & 0.001 \\
\hline Inflammatory/vascular (\%) & $10 / 40(25 \%)$ & $16 / 40(40 \%)$ & & \\
\hline \multicolumn{5}{|l|}{ SB finding } \\
\hline Edematous villi and erosions & $4(10 \%)$ & $10(25 \%)$ & $2(3.3 \%)$ & | vs || \\
\hline Angioectasia & $6(15 \%)$ & $0(0 \%)$ & & \\
\hline Varices & 2(5\%)duodenal & $\begin{array}{l}4(10 \%) \text { duodenal } \\
\text { jejunal varix }\end{array}$ & & 0.58 \\
\hline $\begin{array}{l}\text { Edematous villi and erosions } \\
+ \text { angioectasia }\end{array}$ & $4(10 \%)$ & $4(10 \%)$ & & | vs || vs ||| \\
\hline $\begin{array}{l}\text { Edematous villi and erosions } \\
+ \text { varices }\end{array}$ & $2(5 \%)$ jejunal varix & 2(5\%) duodenal varix & & 0.006 \\
\hline Angiodysplasia & $4(10 \%)$ & $4(10 \%)$ & $2(3.3 \%)$ & \\
\hline
\end{tabular}




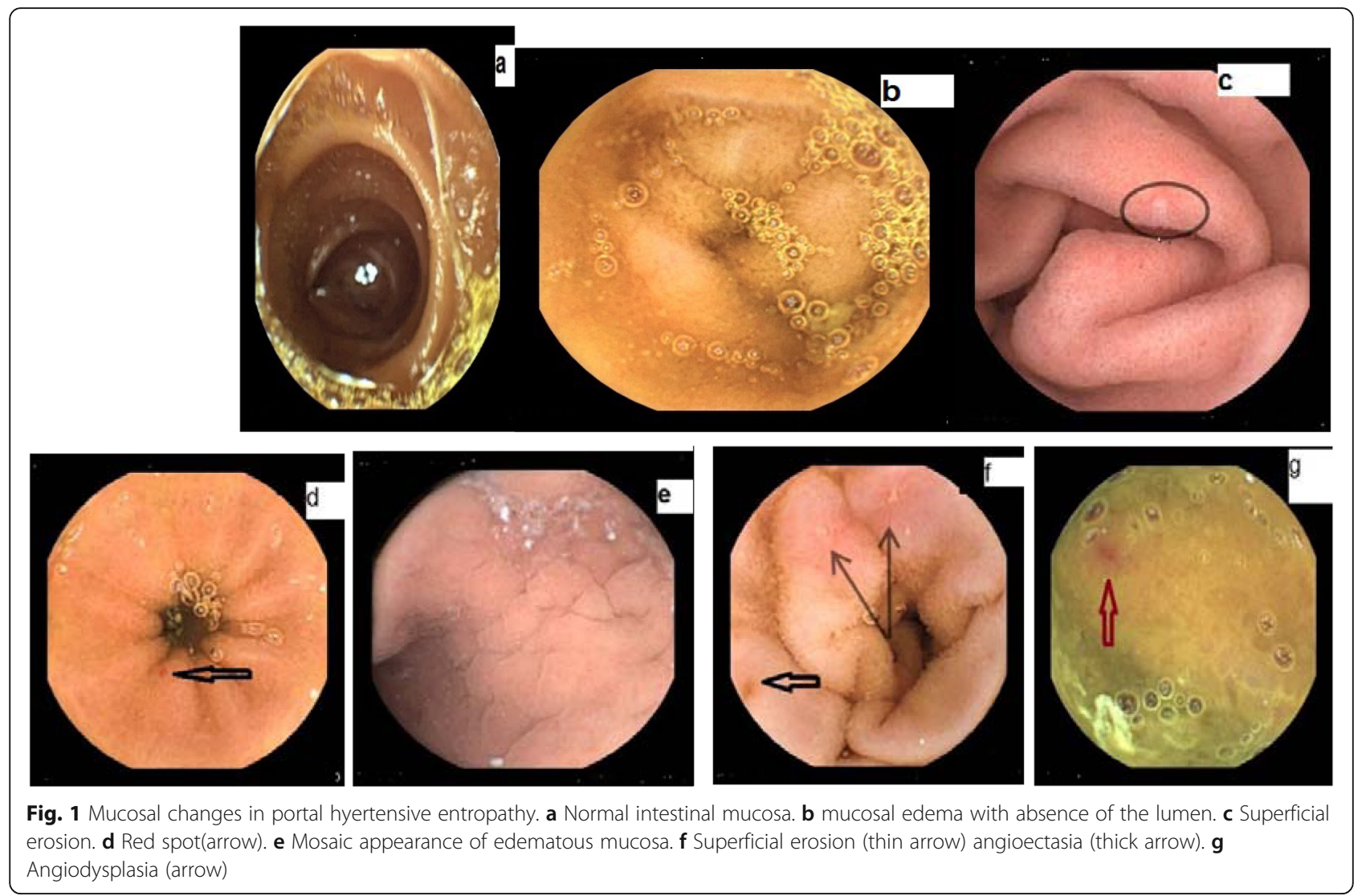

Angiodysplasia $4 / / 40$ (10\%) in group I, $4 / 40$ (10\%) in group II, and 2/60 (3.3\%) in group III.

There was insignificant difference between small-bowel changes between groups I and II $(p=0.58)$ indicating that even in case of absence of esophageal and gastric varices, the small-bowel changes coexist and may cause complications like anemia or obscure GIT bleeding.

We compared between cirrhotic patients with smallbowel changes (PHE) and those cirrhotic without SB changes (Table 2). Small-bowel changes were found in $46 / 80(57.5 \%)$ of cirrhotic patients. We assessed the cirrhotic patients' laboratory results and assessed them clinically using MELD score and Child's classification. Patients with small-bowel changes had a MELD score higher than patients without SB changes $(19.52 \pm 4.03$ vs $11.06 \pm 3.79 p<0.001)$.

SB changes were found in patients with Child's class B and $\mathrm{C}$ than class $\mathrm{A}$ with a significant difference $(p<$ 0.001), whereas all patients with Child's class $C$ show small-bowel changes (Fig 2).

By comparing the HB levels, it was significantly lower in cirrhotic patients with $\mathrm{SB}$ changes than those without $(6.93 \pm 1.49$ vs $9.08 \pm 1.12 p<0.001)$

According to portal hypertensive gastropathy, it was found to be present in all patients with SB changes (PHE) 46/46 (100\%) (Table 2).
In univariate analysis, we studied different factors (age, sex, Child score, MELD score, portal hypertensive gastropathy, and gastric or esophageal varices); out of these factors, Child score, MELD score, portal hypertensive gastropathy, and gastric or esophageal varices were the statistically significant predictors for the occurrence of portal hypertensive enteropathy (OR $(95 \%$ CI) 25

Table 2 Comparison between cirrhotic patients with and without small bowel changes

\begin{tabular}{llll}
\hline & $\begin{array}{c}\text { Small bowel finding } \\
46 / 80(57.5 \%)\end{array}$ & $\begin{array}{l}\text { No small bowel finding } \\
34 / 80(42.5 \%)\end{array}$ & $\begin{array}{l}p \\
\text { value }\end{array}$ \\
\hline $\begin{array}{llll}\text { MELD score } \\
\text { Mean } \pm \text { SD }\end{array}$ & $19.52 \pm 4.03$ & $11.06 \pm 3.79$ & $0.001^{*}$ \\
Child score & & & \\
A & 4 & 24 & $0.001^{*}$ \\
B & 24 & 10 & \\
C & 18 & 0 & $0.001^{*}$ \\
HB level & & & \\
Mean \pm SD & $6.93 \pm 1.49$ & $9.08 \pm 1.12$ & \\
Portal hypertensive gastropathy & & $18(53 \%)$ & \\
Yes & $46(100 \%)$ & $16(47 \%)$ & \\
No & O(0\%) & &
\end{tabular}

MELD model of end-stage liver disease 


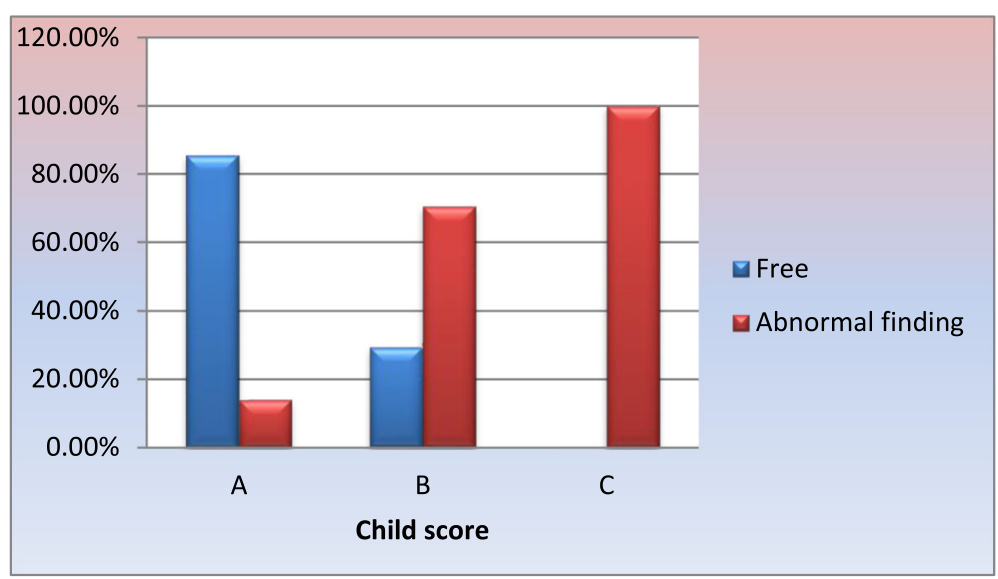

Fig. 2 Percentage of Child score in small-bowel findings

(4.222-150.4), 1.425 (1.239-1.640), 46 (9.112-232.2), $0.291(0.146-0.578)$ respectively) $p<0.001$ for all (Table 3).

Multivariate analysis model further showed that portal hypertensive gastropathy is the independent indicator for portal hypertensive enteropathy OR (20.133) 95\% CI (1.129-358.9) $p=0.041 *$ (Table 4).

Small-bowel findings were positively correlated with Child Score and MELD score with significant value( $r=$ $0.670,0.737$,respectively, $p<0.001)$, and negatively correlated with HB Level( $r=-0.665, p=0.001)$ (Table 5).

By comparing the diagnostic accuracy of $\mathrm{CE}$ and single-balloon enteroscopy, we found that $\mathrm{CE}$ detected SB abnormalities in $75 \%$ vs $40 \%$ for enteroscopy with a significant difference $p=0.025$ (Fig. 3).

\section{Discussion}

Liver cirrhosis is the most advanced stage of chronic liver disease that is defined as a diffuse disorganization of hepatic architecture by extensive fibrosis associated with regenerative nodules [3]. Cirrhosis is associated with high morbidity and mortality, mainly from hepatic insufficiency and portal hypertension (PHT) [9]. Portal

Table 3 Simple logistic regression analysis of factors affecting $\mathrm{PHE}$

\begin{tabular}{llll}
\hline Variable & OR & $95 \% \mathrm{Cl}$ & $p$ value \\
\hline Age & 0.957 & $(0.897-1.021)$ & 0.183 \\
Sex & 0.821 & $(0.308-2.194)$ & 0.695 \\
Child score & & & \\
$\quad$ A & 1 & Ref & - \\
$\quad$ B/C & 25 & $4.222-150.4$ & $0.0001^{*}$ \\
MELD score & 1.425 & $(1.239-1.640)$ & $0.0001^{*}$ \\
PHG & 46 & $(9.112-232.2)$ & $0.0001^{*}$ \\
Gastric esophageal varices & 0.291 & $(0.146-0.578)$ & $0.0001^{*}$ \\
\hline
\end{tabular}

hypertension leads to mucosal abnormalities of the gastrointestinal tract, which are named according to the anatomical site. While portal hypertensive gastropathy and colopathy are considered sources of non-variceal bleeding in patients with liver cirrhosis and portal hypertension, data on portal hypertensive enteropathy (PHE) are limited [10]. This is important in the view of the massive surface area of the small bowel and its unreachability during conventional gastrointestinal endoscopy [11]. The development of capsule endoscopy (CE) and balloon-assisted enteroscopy (BAE) has enabled easy access to the small bowel [12].

In this prospective case-controlled study, 80 cirrhotic patients with portal hypertension with or without gastric or esophageal varices, as well as age- and sex-matched 60 controls, were recruited. We evaluated the smallbowel changes in all study participants using capsule endoscopy or single-balloon enteroscopy.

In our study, we found that the prevalence of smallbowel changes that meet the definition of portal hypertensive enteropathy (PHE) to be statistically significantly higher in cirrhotic patients than controls $(p<0.001)$.

Table 4 Multiple logistic regression analysis of variables affecting PHE

\begin{tabular}{llll}
\hline Variable & OR & $95 \% \mathrm{Cl}$ & $p$ value \\
\hline Age(years) & 1.033 & $(0.921-1.158)$ & 0.583 \\
Sex & 0.144 & $(0.016-1.268)$ & 0.0 .081 \\
Child score & & & \\
$\quad$ A & 1 & Ref & - \\
$\quad$ B/C & 0.009 & $0000-2.394$ & 0.099 \\
MELD score & 1.786 & $(0.881-3.62)$ & 0.107 \\
PHG & 20.133 & $(1.129-358.9)$ & $0.041^{*}$ \\
Gastric esophageal varices & 2.803 & $(0.537-14.64)$ & 0.222 \\
\hline $\begin{array}{l}\text { OR odds ratio, Cl confidence interval, MELD model of end-stage liver disease, PHG } \\
\text { portal hypertensive gastropathy }\end{array}$ & & &
\end{tabular}


Table 5 Correlation between small-bowel findings and Child score, Meld score, and HB level

\begin{tabular}{lll}
\hline Child score & $r$ & 0.670 \\
Meld score & $p$ & $<0.001^{*}$ \\
& $r$ & 0.737 \\
HB level & $p$ & $<0.001^{*}$ \\
& $r$ & -0.665 \\
& $p$ & $<0.001^{*}$ \\
\hline
\end{tabular}

MELD model of end-stage liver disease, $P H G$ portal hypertensive gastropathy, $H B$ hemoglobin

*Significant difference ( $p$ value $\leq 0.05)$

PHE was seen in $57.5 \%$ of cirrhotic patients versus in $6.6 \%$ of control subjects. Our data are consistent with previous studies showed that the prevalence of PHE was significantly higher in cirrhotic patients than in control group [5-7]. Abdelaal et al. found relatively similar results with PHE found in $67.7 \%$ of cirrhotic patients vs $6.9 \%$ in control; $p=0.001$ [7]. On the contrary, in a study by Kodama et al. and colleagues, they showed higher results in cirrhotic patients up to $90 \%$, and they didn't find any small-bowel changes in control subjects [13]. Also, in a study by Akyuz et al., they found smallbowel changes in $92.8 \%$ of cirrhotic patients and in $85.7 \%$ of non-cirrhotic patients who suffered portal hypertension for various reasons [14]. A study by Kovacs et al. showed the same results of our study in cirrhotic patients but much higher percent was seen in the control group than in our study [15], but this was attributed to phenotype of the control group in that study who were non cirrhotic but with PHT.

In our study, there were no significant differences between cirrhotic patients with known esophageal or gastric varices and those without esophageal or gastric varices regarding the prevalence of small-bowel changes $(p=0.58)$. Our data are consistent with many studies $[13,14,16]$. On the other hands, studies by De Palma et al., Abdelaal et al., Goulas et al., and Aoyama et al. showed that there was a correlation between the presence of esophageal or gastric varices and the prevalence of small-bowel changes especially in cases of large esophageal varices and in patients who had history of endoscopic variceal injection sclerotherapy or ligation $[6$, $7,17,18]$.

In this study, the detected SB mucosal changes in cirrhotic patients with esophageal or gastric varices were identical to those seen in cirrhotic patients without varices. The observed changes include edematous villi and erosions in $25 \%$ of cirrhotic patients with varices and in $10 \%$ of cirrhotic patients without varices, angioectasia in $15 \%$ of cirrhotic patients without varices and not detected in cirrhotic patients with varices, small-bowel duodenal varices in 5\% of cirrhotic patients without esophageal varices, and in $10 \%$ of those with known esophageal varices; however, jejunal varices detected to be $5 \%$ in group I. Small-bowel varices were found mainly in duodenal and jejunal regions. This in agreement with Aoyama et al., who found that the proximal and middle small intestines to be the most common sites of involvement by PHE especially varices formation [18]. Patterns of SB changes in our study were similar to other studies $[9,16,19]$. However, in a study published by Figueiredo et al., they showed a higher percentage of SB varices than in our study [20].

In our study, capsule endoscopy has detected smallbowel changes in $75 \%$ of cirrhotic patients, while antegrade single-balloon enteroscopy has detected smallbowel changes in only $40 \%$ of cirrhotic patients ( $p=$ 0.025). These results indicate that capsule endoscopy is more efficient in detection of small-bowel changes in cirrhotic patients than single-balloon enteroscopy. Our

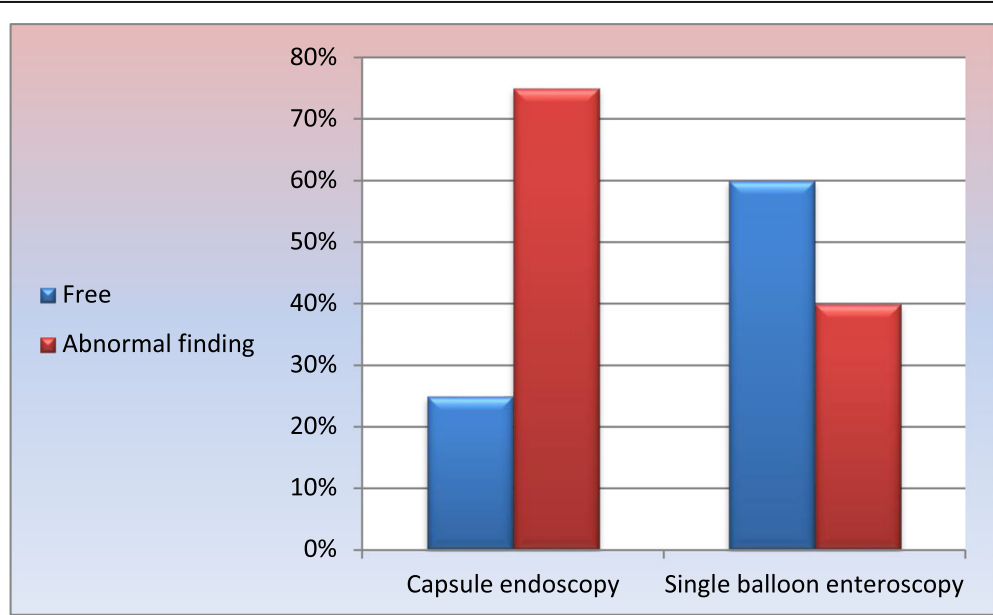

Fig. 3 Capsule endoscopy versus single-balloon enteroscopy in small-bowel findings 
results are consistent with many studies which confirm that capsule endoscopy is a non-invasive technique that is effective in the detection of small-bowel changes and also safe for patients with small-bowel varices who are at high risk of hemorrhage $[11,14,16,21]$. On the other hand, a study by Jeon et al. showed a limitation of CE with inability to do repeated examination and to perform concurrent treatment [22].

In our study, all patients with SB changes were found to have portal hypertensive gastropathy. While those who did not have any small-bowel changes, $53 \%$ of them were found to have PHG. The occurrence of PHG with PHE in previous studies has led to the suggestion that they may not be separate entities but, instead, may be regional indicators of PHT [11, 13, 17]. On the contrary, studies by Kovacs et al., Akyuz et al., and Jeon et al. demonstrated that the presence of small-bowel changes was not related to the presence of portal hypertensive gastropathy [14, 22].

Our study is consistent with several other studies which revealed that patients with advanced cirrhotic status (higher MELD and child Pugh scores) have a higher prevalence of PHE. These data indicate that the presence of small-bowel changes due to portal hypertensive enteropathy is related to the severity of underlying chronic liver disease [10, 16, 18, 23].

We found that the hemoglobin level was significantly lower in cirrhotic patients with small-bowel changes than in those without small-bowel changes $(p<0.001)$. This may be attributed to chronic gastrointestinal bleeding from vascular mucosal lesions that could be concealed and detected only by occult blood in stool $[5,6$, 13].

We studied the effect of different variables on the presence of portal hypertensive enteropathy; we found that by univariate analysis, Child class B or C, high MELD score, portal hypertensive gastropathy, and esophageal and gastric varices could be an indicator of the presence of small-bowel changes $(p<0.05)$, while by multivariate analysis, portal hypertensive gastropathy is the only variable which was related to the presence of small-bowel changes $(\mathrm{OR}=20.133, p=0.41)$, this in agreement with many previous studies $[6,7,15,19-23]$.

\section{Conclusion}

Portal hypertensive enteropathy is found in about half of the studied cirrhotic patients. The presence of current or previous esophageal or gastric varices does not affect the presence of PHE and does not have influence on the type of small bowel mucosal changes. PHG was an independent variable indicating the presence of PHE, but the presence of PHG does imply the absolute presence of PHE. The presence of PHE may be a marker of severity since the prevalence of PHE is higher in patients with advanced chronic liver disease. Regarding diagnosis, small-bowel capsule endoscopy is a more reliable and superior diagnostic modality of PHE than single-balloon enteroscopy. We recommend the use of capsule endoscopy in screening and initial diagnosis of the small-bowel changes in cirrhotic patients especially in patients either advanced chronic liver disease and unexplained GI blood loss, or portal hypertensive gastropathy. Further studies on a larger number of patients are needed to compare the diagnostic accuracy of small-bowel capsule endoscopy and balloon enteroscopy.

\section{Abbreviations}

CBC: Complete blood countGITGastrointestinal tractHBVHepatitis B virusHCVHepatitis C virusPHCPortal hypertensive colopathyPHEPortal hypertensive enteropathyPHGPortal hypertensive gastropathyMELDModel of end-stage liver diseaseSBSmall boweIVCEVideo capsule endoscopy

\section{Acknowledgements}

The authors would like to thank all the participants in this work from the patients to the medical assistant staff.

\section{Authors' contributions}

ZS: study concept and design, writing paper; AE: critical revision of the manuscript; HK: statistical analysis, revision of the manuscript; AME: technical and material support; IM, NF: analysis and interpretation of data. All authors have read and approved the manuscript.

\section{Funding}

None.

\section{Availability of data and materials} Available.

\section{Ethics approval and consent to participate}

This study was conducted in accordance with the principles established by the 18th World Medical Assembly (Helsinki, 1964). This study was conducted in compliance with all national and international laws and regulations. Written informed consent was obtained from all participants in this study. Ethical committee referral number 198.2017, Minia University, Minya Egypt.

\section{Consent for publication}

All patients included in this research gave written informed consent to publish the data contained within this study. Patients involved in this study agree for publication of data.

\section{Competing interests}

The authors declare that they have no competing interests.

\section{Author details}

'Department of Tropical Medicine; Faculty of Medicine, Minia University, Aswan-Cairo Agricultural Road, El-Minya 61111, Egypt. ${ }^{2}$ Department of Internal Medicine; Faculty of Medicine, Minia University, Minya, Egypt. ${ }^{3}$ Police Authority Hospital Agouza, Giza, Egypt. ${ }^{4}$ Department of Gastroenterology and Endoscopy, Theodor Bilharz Research Institute (TBRI), Cairo, Egypt.

Received: 1 November 2019 Accepted: 6 February 2020

Published online: 22 April 2020

\footnotetext{
References

1. Kandeel A, Genedy M, El-Refai S, Funk AL, Fontanet A, Talaat M (2017) The prevalence of hepatitis C virus infection in Egypt 2015: implications for future policy on prevention and treatment. Liver Int 37(1):45-53

2. Ismail SA, Cuadros DF, Benova L (2017) Hepatitis B in Egypt: A crosssectional analysis of prevalence and risk factors for active infection from a nationwide survey. Liver Int 37(12):1814-1822
} 
3. Poynard T, Bedossa P, Opolon P (1997) Natural history of liver fibrosis progression in patients with chronic hepatitis C. The OBSVIRC, METAVIR, CLINIVIR, and DOSVIRC groups. Lancet. 349(9055):825-832

4. Rondonotti E, Villa F, Signorelli C, de Franchis R (2006) Portal hypertensive enteropathy. Gastrointest Endosc Clin N Am 16(2):277-286

5. Al-Azzawi Y, Spaho L, Mahmoud M, Kheder J, Foley A, Cave D (2018) Video Capsule Endoscopy in the Assessment of Portal Hypertensive Enteropathy. Int J Hepatol 2018:5109689

6. De Palma GD, Rega M, Masone S, Persico F, Siciliano S, Patrone F et al (2005) Mucosal abnormalities of the small bowel in patients with cirrhosis and portal hypertension: a capsule endoscopy study. Gastrointest Endosc 62(4):529-534

7. Abdelaal UM, Morita E, Nouda S, Kuramoto T, Miyaji K, Fukui H et al (2010) Evaluation of portal hypertensive enteropathy by scoring with capsule endoscopy: is transient elastography of clinical impact? J Clin Biochem Nutr 47(1):37-44

8. Gross CR, Malinchoc M, Kim WR, Evans RW, Wiesner RH, Petz JL et al (1999) Quality of life before and after liver transplantation for cholestatic liver disease. Hepatology. 29(2):356-364

9. Bosch J, Garcia-Pagan JC (2000) Complications of cirrhosis. I. Portal hypertension. J Hepatol 32(1 Suppl):141-156

10. Tsai CJ, Sanaka MR, Menon KV, Vargo JJ (2014) Balloon-assisted enteroscopy in portal hypertensive enteropathy. Hepatogastroenterology. 61(134):16351641

11. Koulaouzidis A, Rondonotti E, Karargyris A (2013) Small-bowel capsule endoscopy: a ten-point contemporary review. World J Gastroenterol 19(24): 3726-3746

12. Yamamoto H, Yano T, Kita H, Sunada K, Ido K, Sugano K (2003) New system of double-balloon enteroscopy for diagnosis and treatment of small intestinal disorders. Gastroenterology 125(5):1556 author reply -7

13. Kodama M, Uto H, Numata M, Hori T, Murayama T, Sasaki F et al (2008) Endoscopic characterization of the small bowel in patients with portal hypertension evaluated by double balloon endoscopy. J Gastroenterol 43(8): 589-596

14. Akyuz F, Pinarbasi B, Ermis F, Uyanikoglu A, Demir K, Ozdil S et al (2010) Is portal hypertensive enteropathy an important additional cause of blood loss in portal hypertensive patients? Scand J Gastroenterol 45(12):1497-1502

15. Kovacs M, Pak P, Pak G, Feher J, Racz I (2009) Small bowel alterations in portal hypertension: a capsule endoscopic study. Hepatogastroenterology. 56(93):1069-1073

16. Dabos KJ, Koulaouzidis A (2014) Portal hypertensive enteropathy, occult bleeding, and capsule endoscopy: where do we go from here? Dig Dis Sc 59(5):899-901

17. Goulas S, Triantafyllidou K, Karagiannis S, Nicolaou P, Galanis P, Vafiadis I et al (2008) Capsule endoscopy in the investigation of patients with portal hypertension and anemia. Can J Gastroenterol 22(5):469-474

18. Aoyama T, Oka S, Aikata H, Igawa A, Nakano M, Naeshiro N et al (2015) Major predictors of portal hypertensive enteropathy in patients with liver cirrhosis. J Gastroenterol Hepatol 30(1):124-130

19. Al-Azzawi Y, Spaho L, Mahmoud M, Kheder J, Foley A, Cave D (2018) Video Capsule Endoscopy in the Assessment of Portal Hypertensive Enteropathy. International journal of hepatology 2018:5109689

20. Figueiredo P, Almeida N, Lerias C, Lopes S, Gouveia H, Leitao MC et al (2008) Effect of portal hypertension in the small bowel: an endoscopic approach. Dig Dis Sci 53(8):2144-2150

21. Mekaroonkamol P, Cohen R, Chawla S (2015) Portal hypertensive enteropathy. World J Hepatol 7(2):127-138

22. Jeon SR, Kim JO, Kim JB, Ye BD, Chang DK, Shim KN et al (2014) Portal hypertensive enteropathy diagnosed by capsule endoscopy in cirrhotic patients: a nationwide multicenter study. Dig Dis Sci 59(5):1036-1041

23. Otani I, Oka S, Tanaka S, Tsuboi A, Kunihara S, Nagaoki Y et al (2018) Clinical significance of small-bowel villous edema in patients with liver cirrhosis: A capsule endoscopy study. J Gastroenterol Hepatol 33(4):825-830

\section{Publisher's Note}

Springer Nature remains neutral with regard to jurisdictional claims in published maps and institutional affiliations.

\section{Submit your manuscript to a SpringerOpen ${ }^{\circ}$ journal and benefit from:}

- Convenient online submission

- Rigorous peer review

- Open access: articles freely available online

- High visibility within the field

- Retaining the copyright to your article

Submit your next manuscript at $\boldsymbol{\nabla}$ springeropen.com 